This material is protected by U.S. copyright law. Unauthorized reproduction is prohibited. To purchase quantity reprints, please e-mail reprints@ons.org or to request permission to reproduce multiple copies, please e-mail pubpermissions@ons.org.

\title{
Living With Cancer: The Journey From Victim to Survivor
}

"It is, of course, likely that the language about cancer will evolve in the coming years. It must change decisively, when the disease is finally understood and the rate of cure becomes much higher."

$$
\text { -S. Sontag, 1978, p. } 88
$$

We all know the statistics. Today, more than 10.5 million cancer survivors, representing $3.6 \%$ of the population, are living in the United States (National Cancer Institute, 2006). Much has changed in the decades since Sontag (1978) wrote Illness as Metaphor and articulated our societal perceptions that cancer $=$ death and people with cancer were victims.

On May 6, 2007, the Discovery Channel aired a three-hour television program hosted by Ted Koppel, Living With Cancer, that was part documentary and part town hall meeting. The town hall portion of the program featured Leroy Sievers ${ }^{\mathrm{a}}$, an award-winning journalist with metastatic colon cancer; Senator John Edwards's wife, Elizabeth Edwards ${ }^{\mathrm{b}}$, an attorney, who has metastatic breast cancer; and Lance Armstrong ${ }^{c}$, a former professional racing cyclist and seven-time Tour de France winner who is in complete remission from metastatic testicular cancer. They discussed their experiences in coping with cancer and represented the range of survivors we work with-one in complete remission and considered

\footnotetext{
a Sievers' blog and podcast, "My Cancer," are available on National Public Radio at www.npr.org/tem plates/story/story.php?storyld=5503400.

${ }^{\mathrm{b}}$ Edwards (2006) is the author of Saving Graces: Finding Solace and Strength From Friends and Strangers.

'Armstrong founded the Lance Armstrong Foundation (www.livestrong.org).
}

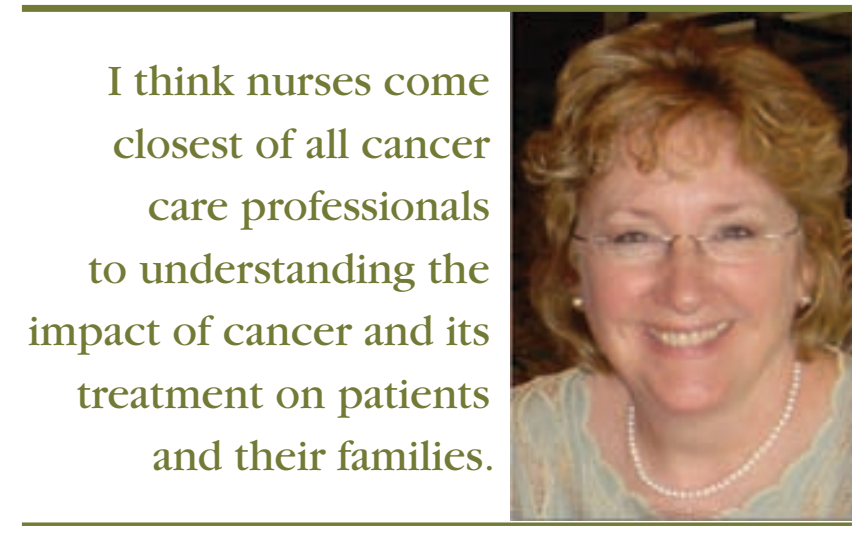

Sievers, Edwards, and Armstrong discussed the partnering role of various healthcare providers in dealing and living with cancer. Physicians were clearly their partners related to treatment and disease management and were discussed using various metaphors (e.g., the can-

cured, one facing a recurrence, and one living with advanced metastatic disease.

Many things struck me about the program. First, I was surprised that it was produced. A three-hour program discussing cancer is so different from the days when people whispered about or alluded to the disease indirectly. The topic is now part of our society's daily discourse. Second, the show followed Sievers' life over many months and featured comments from Edwards and Armstrong about their experiences. They described the changing nature of living with cancer and how they adapted to it on an almost daily basis

As nurses, I think we come closest of all cancer care professionals to understanding the impact of cancer and its treatment on patients and their families. Even so, that understanding is not the same as living with the disease day in and day out. I was reminded how pervasive the effects of the disease and its treatment still are-despite the tremendous progress we have made. The program also reminded me that we only really have a snapshot-not a video-of the lives patients are living with cancer. cer team's quarterback, captain of the team).

Although military metaphors may still be used (e.g., winning the battle), they are being replaced by competitive and sports metaphors (Penson, Schapira, Daniels, Chabner, \& Lynch, 2004). Perhaps that trend reflects Armstrong's influence on survivorship. The metaphoric cancer journey is also entering the language of many survivors.

An oncology nurse was present in Sievers' video clips but only peripherally, which may or may not have been an artifact of the editing process. Any real discussion of the role of oncology nurses in cancer care did not occur until the town hall portion of the program. Oncology Nursing Society President Georgia M. Decker, MS, RN, CS-ANP, AOCN ${ }^{\circledR}$, was in the audience and asked Sievers, Edwards, and Armstrong about the presence and role of oncology nurses. Sievers recognized his nurse in the audience and talked about how she was his partner on his journey in a very different way

Digital Object Identifier: 10.1188/07.CJON.481-482 
than his physician. His description was reminiscent of Ellyn Bushkin's, RN, MSN, (1993) in her Mara Mogensen Flaherty Memorial Lecture titled "Signposts of Survivorship," whereby guides and fellow travelers joined the cancer survivor to help on the journey. The guides and travelers were not tourists who visited occasionally but were important and essential parts of the cancer journey. Edwards said that every patient with cancer could name his or her oncology nurse, which was confirmed by the murmurings from the audience. That was reassuring, but it made me wonder: Why were we less visible? Does every patient with cancer need an oncology nurse? Does every patient with cancer have an oncology nurse? What will happen if there aren't enough oncology nurses? We need to think about what and how we do what we do so that every patient has an oncology nurse or is able to benefit from our expertise in some other way to guide them along.

Sontag (1978) was prescient in her vision of moving away from calling those with cancer victims. In the past 30 years, a metaphoric shift from victim to survivor has occurred. Life before and after cancer has entered the lexicon of the survivor, reflecting Mullan's (1985) observation that life is forever altered by the cancer experience. We need to fully understand what it means to be a survivor and address the range of issues faced on the journey living with cancer. Living With Cancer brought that point home.

\section{References}

Bushkin, E. (1993). Signposts of survivorship. Oncology Nursing Forum, 20, 869-875.

Edwards, E. (2006). Saving graces: Find- ing solace and strength from friends and strangers. New York: Broadway Books.

Mullan, F. (1985). Seasons of survival: Reflections of a physician with cancer. New England Journal of Medicine, 313, 270-273.

National Cancer Institute. (2006). Estimated U.S. cancer prevalence counts: Who are our cancer survivors in the U.S.? Retrieved July 18, 2007, from http://dccps.nci.nih .gov/ocs/prevalence/index.html

Penson, R.T., Schapira, L., Daniels, K.J., Chabner, B.A., \& Lynch, T.J. (2004). Cancer as metaphor. Oncologist, 9, 708-716.

Sontag, S. (1978). Illness as metaphor. New York: Farrar, Straus, and Giroux.

\section{Spot on Living With Cancer ...}

More information about the Discovery Channel's program, Living With Cancer, is available online at http://dsc.discovery.com/convergence/kop pel/koppel.html. Special features include program highlights and behindthe-scenes footage with Lance Armstrong and Elizabeth Edwards. 